\title{
Laboratory studies on patients receiving anticoagulant therapy
}

\author{
S. SHAW, G. D. PEGRUM, AND S. WOLFF \\ From the Department of Haematology, Charing Cross Hospital Medical School, London
}

SYNOPSIS An investigation into the laboratory control of anticoagulant therapy is presented. The cases were divided into those in the first few weeks of therapy and those on long-term treatment. Variations in the levels of factors VII and X, and factor IX were assessed. Thromboplastin levels were used to control therapy. These were compared with parallel estimations by Thrombotest and with the levels of the coagulation factors. Thrombotest was found to have no major advantage over thromboplastin.

The control of anticoagulant therapy, especially in patients receiving long-term anticoagulants, has never been entirely satisfactory. There has been a continued search for improved methods to warn of impending haemorrhage.

The one-stage prothrombin time (Quick, 1935) has been the basis of the control of anticoagulant therapy until recent years. This test is sensitive to changes in factor $V$, which is unaffected by anticoagulants, and is insensitive to variations in factor IX which is depressed by these drugs.

Many use the prothrombin time with other estimations. Sise, Lavelle, Adamis, and Becker (1958) carried out the Quick one-stage test and also measured the prothrombin time. Bachmann, Duckert, and Koller (1958) suggested the use of factor X levels together with the one-stage prothrombin time. The prothrombin and proconvertin method of control was used by Owren and Aas in 1951, and more recently Owren (1959) introduced the Thrombotest reagent. This reagent was considered to be sensitive to all blood clotting factors depressed by oral anticoagulants, viz., prothrombin (factor II), proconvertin (factor VII), Christmas factor (factor IX), and Stuart-Prower factor (factor X).

We recently reviewed our method of controlling anticoagulant therapy. A comparison was made between three commercial thromboplastins and Thrombotest. One thromboplastin was compared directly with Thrombotest on a series of patients receiving either phenindione or wafarin or dicoumoxane. The levels of combined factors VII plus X, factor X, and factor IX were studied on a series of patients on short-term and long-term anticoaguReceived for publication 25 November 1964. lants. These factors were chosen because Bachmann et al. (1958) and Owren (1961) pointed out that severe bleeding in patients on short-term anticoagulants was associated with a marked reduction in factor X and to a lesser extent in factor VII; suppression of IX and $X$ is mainly responsible for haemorrhage in patients receiving long-term anticoagulants. Estimations of these factors were made, and the one-stage prothrombin time and Thrombotest carried out on the same sample of blood; these results were correlated.

\section{METHODS}

Blood was obtained from the patients by venepuncture using plastic disposable syringes, and $1.8 \mathrm{ml}$. was placed in a polystyrene bottle containing $0.2 \mathrm{ml}$. of $3.2 \%$ sodium citrate, and centrifuged within two hours. The plasma was stored at $-20^{\circ} \mathrm{C}$. for up to three days. At the same time $5 \mathrm{ml}$. of blood was placed in a glass tube and allowed to clot overnight, the serum being separated by centrifugation and stored at $-20^{\circ} \mathrm{C}$.

A one-stage prothrombin time was carried out as recommended by the individual thromboplastin vendors. For two of these methods $0.2 \mathrm{ml}$. of thromboplastincalcium chloride mixture was added to $0.1 \mathrm{ml}$. of patients' plasma at $37^{\circ} \mathrm{C}$., and the clotting time recorded. In the third clotting time was recorded after the calcium chloride was added to the mixture of plasma and thromboplastin.

The various thromboplastins were compared using dilutions of normal citrated plasma made with aluminaabsorbed normal plasma (deficient in prothrombin, factors VII, IX, and X). Prothrombin times were carried out on the various dilutions with the three thromboplastins. The Thrombotest coagulation time (using the supplier's method, and on plasma) was also recorded on these dilutions. 
The coagulation factors were estimated on the same sample of blood as that used for the prothrombin time and Thrombotest.

ESTIMATION OF COMBINED FACTORS VII PLUS X BY THROMBOPLASTIN CLOTTING TIMES A modification of the technique of Denson (1961a) was used. Beef plasma substrate deficient in factors VII and X was prepared as follows:

Wood charcoal, $8 \mathrm{~g}$., was mixed with $25 \mathrm{ml}$. of normal beef plasma (stored at $-20^{\circ} \mathrm{C}$.) in a screw-capped bottle. The mixture was kept at $4^{\circ} \mathrm{C}$. and inverted eight times a day for four days. The plasma was then separated by centrifugation and tested for the lack of factors VII and $\mathrm{X}$ and the presence of prothrombin, using the methods described by Denson (1961a).

Dilutions of normal citrated plasma from $1 / 10$ to $1 / 10,000$ were prepared using veronal buffer $(p \mathrm{H} 7 \cdot 35)$. Of these dilutions, $0.1 \mathrm{ml}$. was added to $0 \cdot 1 \mathrm{ml}$. of beefplasma substrate, and the clotting times recorded after the addition of $0.2 \mathrm{ml}$. of thromboplastin-calcium chloride mixture.

A calibration curve was plotted of the clotting times against the dilutions, $1 / 10$ dilution taken as $100 \%$, and $1 / 10,000$ as $0 \cdot 1 \%$, activity. The level in the individual patients was assessed using citrated plasma diluted 1/10 with veronal buffer $(p \mathrm{H} \mathrm{7.35)}$ which was added to an equal volume of the charcoal-absorbed beef plasma; the clotting time was recorded after adding thromboplastin and calcium chloride. The percentage of the combined factors VII and X was then obtained from the calibration curve.

ESTIMATION OF FACTOR X BY 'STYPVEN' CLOTTING TIMES A similar calibration curve of clotting times against dilutions was prepared with charcoal-absorbed beef plasma substrate using lecithinized stypven instead of thromboplastin. The lecithinized stypven was prepared as follows:

Russell's viper venom (stypven) was diluted with veronal buffer $(p \mathrm{H} 7 \cdot 35)$ to $1 / 100,000$. A $10 \%$ solution of ovolecithin in alcohol was prepared, and $0.02 \mathrm{ml}$. added to $1 \mathrm{ml}$. of diluted 'stypven'.

The level of factor $X$ in the patients was assessed by using equal volumes of citrated plasma diluted $1 / 10$ with veronal buffer and beef plasma substrate. The 'stypven' clotting time was recorded and the percentage activity obtained from the calibration curve.

ESTIMATION OF FACTOR IX (CHRISTMAS FACTOR) Thromboplastin-generation tests were carried out by the method of Biggs and Douglas (1953) on each sample of blood. Deficiency of factor IX was demonstrated by the addition of known factor-IX-deficient serum. Dilutions of normal serum with the known deficient serum were prepared. The percentage of factor IX present in the serum was calculated by comparison of the clotting times, using the patients' serum and these dilutions of the normal serum.

\section{RESULTS}

The findings, comparing the various thromboplastins with Thrombotest, are shown in Figure 1.

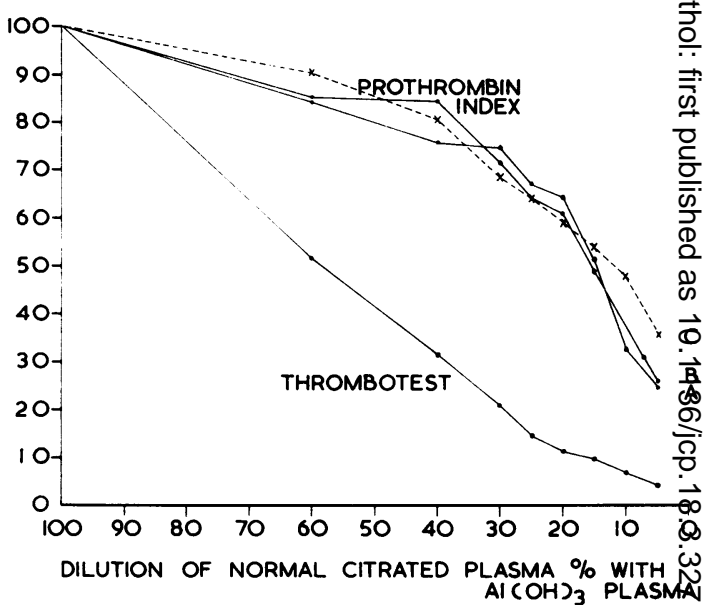

FIG. 1. Comparison of three commercial thromboplast $\mathrm{O}$. and Thrombotest.

The thromboplastins gave very similar curves, but $\mathrm{C}$ appeared to be the most regular. This was prodo ably due to the fact that reagent $C$ had the longesst clotting time, and therefore greater precision in cording was possible.

Over the therapeutic range Thrombotest ga results which were almost linear; thromboplastinac over this range appeared to give the most dirept comparison, and was therefore used in the subsequent investigations.

In our early work we accepted a therapeutic range of 10 to $20 \%$ for the Thrombotest and 45 to $50 \%$ Fr ptothrombin index (Fig. 2). In the majority of tests there was a good correlation of results but $15-20 \%$ of the Thrombotest results fell below the thexpeutic range. In none of these patients were there any haemorrhagic complications. The activity of the various clotting factors estimated was related to the duration of therapy.

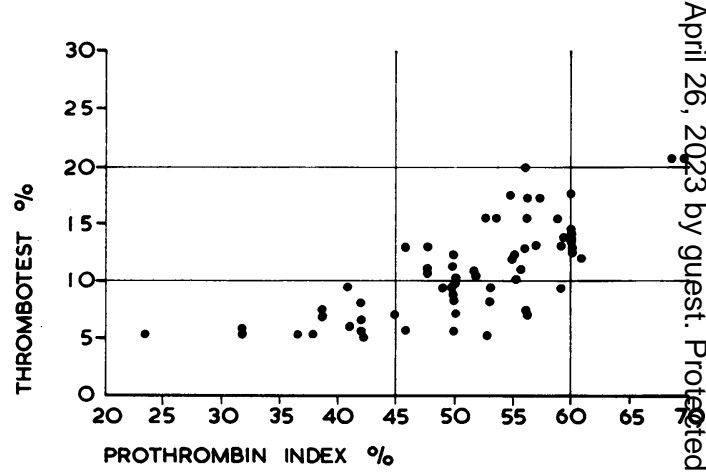

FIG. 2. Correlation between simultaneous estimations ब्र the prothrombin index and Thrombotest. 
Towards the end of the first week when patients were adequately anticoagulated, combined factors VII plus $\mathrm{X}$ and factor $\mathrm{X}$ alone were found to be depressed in all cases. The majority of cases showed levels between 10 and $30 \%$ of normal activity. Factor IX was only moderately depressed in approximately half of these patients. During the second and third weeks, in patients whose prothrombin time was in the therapeutic range, the activity of combined factors VII plus $\mathrm{X}$, and of factor $\mathrm{X}$ remained between 10 and $30 \%$; in about a quarter of the patients the level was in the region of $10 \%$. Factor IX activity was low only in those patients showing the greatest depression of VII and X. Towards the end of the fourth week, and in patients on long-term therapy (one to five years) when factors VII and X were below $5 \%$ there was no measurable factor IX. In five patients out of 24 there was no measurable factor IX when levels of factors VII and X were above $10 \%$. The Thrombotest on these patients was within the therapeutic range. The levels of factor IX showed marked variation in different patients who were considered to be well controlled as assessed by the prothrombin time.

In general, results with Thrombotest and thromboplastin showed a similar degree of sensitivity to depression of factors VII and X.

\section{DISCUSSION}

In this study we found good correlation between the various thromboplastins but the one with the longest clotting time gave the greatest precision in recording. The comparison of this reagent with Thrombotest suggested that the original therapeutic range using Thrombotest was set too high, and a therapeutic level of 7 to $15 \%$ would be more realistic. These findings agree with observations made by Sevitt and Innes (1964) and by Poller (1964).

In an investigation into various coagulation factors on patients receiving phenindione, Denson (1961b) found it difficult to interpret the levels of the various coagulation factors: prothrombin was not greatly reduced when factors VII and X remained high. He also considered that the level of Christmas factor (factor IX) was not severely reduced in the absence of significant depression of the other factors. This latter finding is not confirmed by our work, nor is his finding of low levels of Christmas factor during the first week of therapy.

We chose to estimate factors VII, IX, and X as reduction of these has been shown to be the most important in the initiation of haemorrhage in patients receiving anticoagulants. Factor VII was estimated in combination with factor $\mathrm{X}$ but $\mathrm{a}$ further study to separate factor VII is being done.

The sensitivity of the thromboplastin to the levels of factors VII and X was found to be sufficient to control therapy. The one-stage prothrombin time was the basis of the control in all the patients in this study. We did not use the Thrombotest to modify the dosage of anticoagulants. If we had taken a therapeutic range of 7 to $15 \%$ for the Thrombotest the results would have indicated dangerous levels in eight patients. The thromboplastin time was within the therapeutic range in two of these patients; they had only been on anticoagulants for one week. Factors VII and X were below $10 \%$ at this time; factor IX was depressed to $8 \%$ in one patient but showed no depression in the other.

Thrombotest appears to be insensitive to factor IX deficiency if associated with a moderate degree of depression of factors VII and X. The reputed value of Thrombotest in assessing depression of factor IX may well be due to its sensitivity to marked reduction of factors VII and X. Others have also commented on the insensitivity of Thrombotest to factor IX (Nour-Eldin, 1959; Denson, 1961a, b; Quick and Hussey, 1961). Rapaport and Ames (1962) produced evidence to show that bleeding secondary to excessive depression of factor IX was unlikely in patients well controlled by Quick's one-stage test. In our series of cases, although the level of factor IX was extremely low in some patients, no bleeding occurred.

We do not feel from this series that Thrombotest has any major advantage over the one-stage prothrombin time in the control of anticoagulant therapy. It does, however, have the merit of standardizing control of therapy from one laboratory to another. The use of different thromboplastins makes control more difficult since clotting times vary, and confusion may arise from the different methods used to express results.

We would like to thank the Sub-Committee for Clinical Research, Charing Cross Hospital, for a grant.

\section{REFERENCES}

Bachmann, F., Duckert, F., and Koller, F. (1958). Thromb. Diathes. haemorrh. (Stuttg.), 2, 24.

Biggs, R., and Douglas, A. S. (1953). J. clin. Path., 6, 23.

Denson, K. W. (1961a). Acta haemat. (Basel), 25, 105.

- (1961b). Brit. med.J., 1, 1205.

Nour-Eldin, F. (1959). Lancet, 2, 913

Owren, P. A. (1959). Ibid., 2, 754.

- (1961). Laboratory control of anticoagulant therapy. In Symposium on Anticoagulant Therapy, edited by G. W. Pickering, p. 46. Harvey and Blythe, London.

- and Aas, K. (1951). Scand. J. clin. Lab. Invest., 3, 201.

Poller, L. (1964). Lancet, 1, 719.

Quick, A. J. (1935). J. biol. Chem., 109, 73P.

-, and Hussey, C. V. (1961). New Engl. J. Med., 265, 1286.

Rapaport, S. I., and Ames, S. B. (1962). Ibid., 267, 125.

Sevitt, S., and Innes, D. (1964). Lancet, 1, 124.

Sise, H. S., Lavelle, S. M., Adamis, D., and Becker, R. (1958). New Engl. J. Med., 259, 266. 